\title{
Estimation of the galanthamine using derivative spectrophotometry in bulk drug and formulation
}

\author{
Karan Mittal $^{1}$, Ramni Kaushal ${ }^{1}$, Rajashree Mashru' ${ }^{2}$, Arti Thakkar ${ }^{1}$ \\ ${ }^{1}$ I. S. F. College of Pharmacy, Ferozepur Road, Ghal Kalan, Moga, Punjab, India; \\ ${ }^{2}$ Center of Relevance and Excellence in Novel Drug Delivery Systems, Pharmacy Department, G.H. Patel Building, The Maharaja \\ Sayajirao University of Baroda, Vadodara, India. \\ Email: artirthakkar@gmail.com
}

Received 8 January 2010; revised 20 January 2010; accepted 23 January 2010.

\begin{abstract}
Two simple, rapid, accurate, precise, reliable and economical spectrophotometric methods have been proposed for the determination of galanthamine hydrobromide (GH) in bulk and pharmaceutical formulation. First method is zero order UV spectrophotometry and second is 1st derivative zero crossing spectrophotometry. The developed methods have shown best results in terms of linearity, accuracy, precision, LOD and LOQ for bulk drugs and marketed formulations. Absorbance was measured at $287 \mathrm{~nm}$ for zero order and $277.4 \mathrm{~nm}$ for first derivative. It obeyed Lambert-Beer's law in the range of 30-80 $\mu \mathrm{g} \mathrm{mL-1.} \mathrm{Both}$ methods have good linearity $(\mathrm{r} 2=\mathbf{0 . 9 9 9 7 )}$ ) and accuracy found to be $100.5 \%$ and $101.2 \%$ for both methods respectively.
\end{abstract}

Keywords: Galanthamine Hydrobromide (GH); Zero Order UV-Spectrophotometry; First Derivative Zero Crossing Spectrophotometry

\section{INTRODUCTION}

Figure 1 is the structure of galanthamine hydrobromide (GH), which is $(4 a S, 6 R, 8 a S)-5,6,9,10,11,12$-hexahydro3-methoxy-11-methyl-4a $H$-[1] benzofuro [3a,3,2-ef] [2] benzazepin-6-ol [1,2]. It is used for the treatment of mild to moderate Alzheimer's disease and various memory impairments [3,4]. The molecular weight of GH is 368.27 and melting point is $258-264^{\circ} \mathrm{C}$. GH is very soluble in water [5].

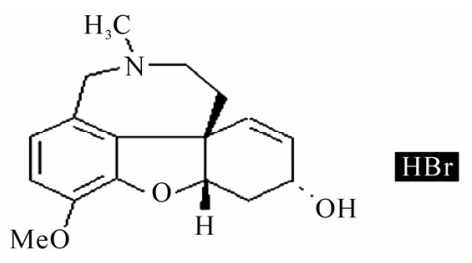

Figure 1. Structure of GH.
The official monograph of USP [6] describes assay method for GH using HPLC but compare to that spectrophotometric methods are more economic and simple. Under computer-controlled instrumentation, derivative spectrophotemetry is playing a very important role in the analysis of drugs by giving more resolved spectra than the zero order spectra $[7,8]$.

The aim of the present work is to investigate utility of derivative spectrophotometry and to develop reliable spectrophotometric procedure for determination of GH either in bulk and marketed formulation.

\section{MATERIALS AND METHODS}

\subsection{Instruments and Reagents}

Spectrophotometric measurements were made on a Shimadzu 1700 double beam UV-VIS spectrophotometer with a fix slit width of $1 \mathrm{~nm}$ coupled with computer loaded with Shimadzu UV PC software (UV probe) version 2.31. Double distilled water was used and pure GH was obtained from Alembic Pharmaceuticals Ltd. Vadodara, India. The marketed formulation of GH was obtained commercially from Sun Pharmaceuticals Ltd (Galmer-40 tablets labeled $4 \mathrm{mg}$ of pure drug, Batch Number-GK 90964).

\subsection{Standard and Test Solutions}

Stock solution of $1 \mathrm{mg}$ mL-1 of pure GH and its formulation was freshly prepared in double distilled water. Test solution of GH was tested for stability in solution during the actual analysis. The behaviour of GH was found to be stable over the period of $24 \mathrm{hr}$ from their preparation at room temperature.

\subsubsection{Zero Order UV-Spectrophotemetry (Method 1)}

The working solutions were prepared by accurately diluting aliquots of the standard solution with water to obtain the concentration in range of 30-80 $\mu \mathrm{g} \mathrm{mL}-1$. The absorption spectra of the samples were recorded between 200-400 nm against double distilled water using a $1.0 \mathrm{~cm}$ 
quartz cell. Zero order spectra of pure drug GH were stored individually within mentioned concentration ranges and absorbance was measured at $280 \mathrm{~nm}$.

\subsubsection{First Derivative Zero Crossing Spectrophotometry (Method 2)}

The zero order absorption spectra of GH were derivatized in first order using delta lambda 4 and scaling factor 10. The first derivative amplitudes were recorded at $277.4 \mathrm{~nm}$.

\section{RESULTS AND DISCUSSION}

The absorption spectra of the GH were recorded at wavelength $287 \mathrm{~nm}$ for zero order UV-spectrophotometry and 1 st derivative was measured at $277.4 \mathrm{~nm}$. It is observed from the spectra that GH shows a good linearity in the range of $30-80 \mu \mathrm{g} \mathrm{mL}-1$. Figure 2 explains the zero order spectra of GH. While, Figure 3 describes first derivative spectra of GH which showed more resolution than zero order spectra. Both methods were validated, all the validation parameters were in limit as per the ICH guidelines [9]. Table 1 exhibits the detailed validation parameters for both the methods. Table 2 represents results of recovery studies of both methods and Table 3

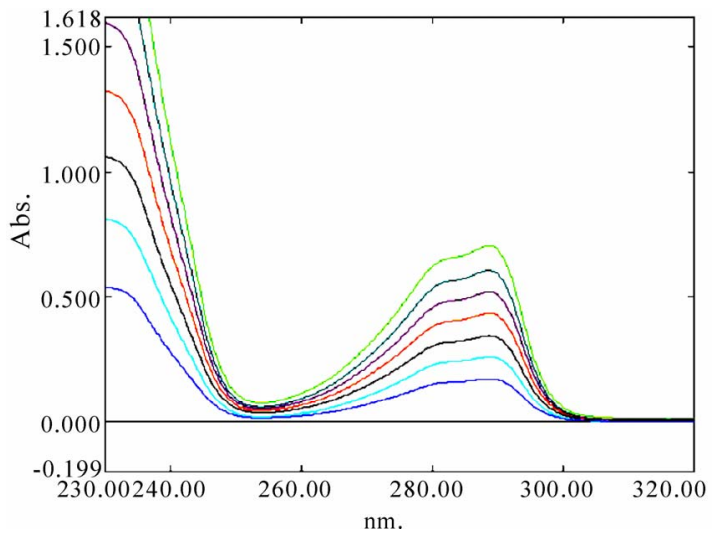

Figure 2. The zero order spectra of GH of $30-80 \mu \mathrm{g} \mathrm{mL}^{-1}$.

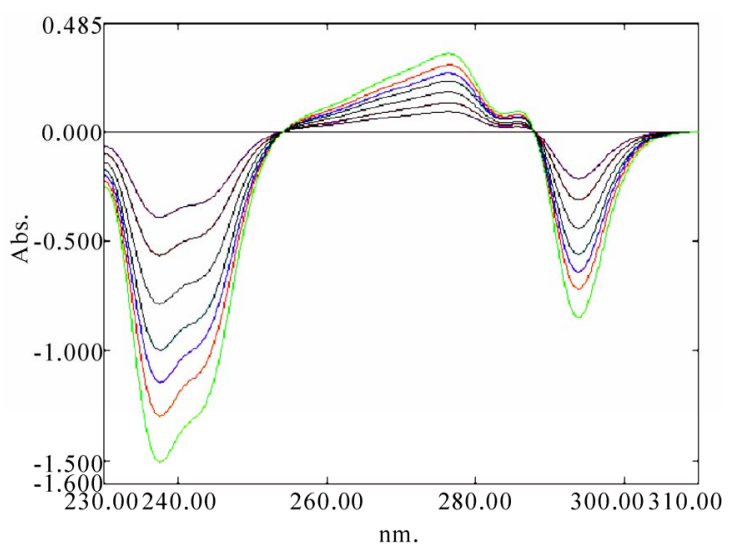

Figure 3. The first derivative spectra of GH of $30-80 \mu \mathrm{g}$ $\mathrm{mL}^{-1}$.
Table 1. Validation parameters obtained by method 1 and method 2 .

\begin{tabular}{lll}
\hline \multicolumn{1}{c}{ Parameters } & \multicolumn{1}{c}{ Method-1 } & \multicolumn{1}{c}{ Method-2 } \\
\hline Linearity & 0.9996 & 0.9997 \\
Range $\left(\mu \mathrm{g} \mathrm{mL}^{-1}\right)$ & $30-80$ & $30-80$ \\
Accuracy & $100.5 \pm 2.39$ & $101.2 \pm 1.63$ \\
Precision & \% R.S.D-0.8315 & \% R.S.D-1.7052 \\
LOD $\left(\mu \mathrm{g} \mathrm{mL}^{-1}\right)$ & 1.46 & 0.72 \\
LOQ $\left(\mu \mathrm{g} \mathrm{mL}^{-1}\right)$ & 4.45 & 2.19 \\
Assay (\%Purity) & 98.02 & 99.94 \\
\hline
\end{tabular}

Table 2. The results of recovery studies of the method 1 and method 2.

\begin{tabular}{lcc}
\hline $\begin{array}{c}\text { Amt added } \\
\left(\mu \mathrm{g} \mathrm{mL}^{-1}\right)\end{array}$ & $\begin{array}{c}\text { \% Recovery } \\
\text { Method 1 }\end{array}$ & $\begin{array}{c}\text { \% Recovery } \\
\text { Method 2 }\end{array}$ \\
\hline 16 & 99.25 & 101.6 \\
20 & 99.05 & 99.4 \\
24 & 103.3 & 102.6 \\
Mean recovery & 100.5 & 101.2 \\
SD & 2.39 & 1.63 \\
\hline
\end{tabular}

Table 3. The statistical comparison of the results of validated methods.

\begin{tabular}{cc}
\hline t-Test & F-Test \\
\hline$t_{\text {calculated }}=0.419$ & $F_{\text {calculated }}=2.14$ \\
$t_{\text {theoretical }}=3.52$ & $F_{\text {theoretical }}=19.0$ \\
\hline
\end{tabular}

explains the statistical comparison of results of both the validated methods.

The results obtained were compared statistically by Student $t$-test and by the variance ratio $F$-test with those obtained by each method. The calculated values of the Student $t$-values at $95 \%$ confidence level and the variance ratio $F$-values did not exceed the theoretical values indicating that there were no significant differences among the results of the developed two methods.

\section{CONCLUSIONS}

The developed spectrophotometric methods for determination of GH are simple, specific, accurate, precise, rapid and economical which indicates its adequacy for routine pharmaceutical analysis. It is concluded that derivative spectrophotometry is successfully utilized for the estimation of GH.

\section{ACKNOWLEDGEMENT}

The authors express their sincere thanks to Mr Bhagirath Patel, F \& D Division, Alembic Pharmaceuticals Ltd. Vadodara, India for supplying 
gift samples of pure Galanthamine hydrobromide and also I.S.F College of Pharmacy, Moga for providing facilities to carry out the research.

\section{REFERENCES}

[1] Ping, J., Rong, S., Jing, Z., Liang, F., Qiaojun, H. and Yongzhou, H. (2008) Design, synthesis and evaluation of galanthamine derivatives as acetylcholinesterase inhibitors. European Journal of Medicinal Chemistry, 44 (12), 772-784.

[2] Traykova, M., Traykov, T., Hadjimitova, V., Krikorian, K. and Bojadgieva, N. (2003) Antioxidant Properties of Gal- antamine Hydrobromide. Zeitschrift für Naturforschung, 58c, 361-365.

[3] Heinrich, M. and Teoh, H.L. (2004) Galanthamine from snowdrop-the development of a modern drug against Alzheimer's disease from local Caucasian knowledge. Journal of Ethno pharmacology, 92, 147-162.

[4] Scott, L.J. and Goa, K.L. (2000) Galantha mine: A review of its use in Alzheimer's disease. Adis Review, 60(5), 1095-122.

[5] Novikova, I.Y. and Tulaganov, A.A. (2002) Physicochemical methods for the analysis of galanthamine (review). Pharmaceutical Chemistry Journal, 36(11), 623-627. 